\title{
II
}

\section{O OBJETO “DESFUNCIONALIZADO”}

Jéssica Luiza P. Cardoso ${ }^{1}$

Resumo: Este trabalho é uma reflexão sobre o poder da criação, transformação e resignificação de objetos. Ele parte de experiências de formação como professora de teatro vindas durante o estágio na Fundação de Artes de Ouro Preto (FAOP), que trouxe como questão a ludicidade no espaço/cenário escolar para a educação em arte, durante a graduação em Artes Cênicas pela Universidade Federal de Ouro Preto (UFOP).

Palavras-chave: lúdico, teatro, licenciatura, objeto, desfuncionalizar.

Eixo Temático: Formação de Professores de Teatro

\section{Introdução}

Espaços de ensino, com escolas formais ou instituições não-formais de educação, são repletos de objetos cujos usos cotidianos não despertam atenção para possíveis criações, são justamente eles o foco da prática desenvolvida. Cadeiras, mesas, armários, portas, cadernos, livros, tesouras, canetas, borrachas, mochilas, e outros inúmeros objetos aguardam para serem descobertos, para serem usados em criações artísticas. Entretanto, esses objetos estão sendo usados com as mesmas funções cotidianamente pelos alunos e professores, assim eles “continuam em espera” de quem os queira moldar.

Este trabalho reflete sobre o ensino de teatro e a formação do professor(a) de teatro a partir da minha experiência no curso de Licenciatura em Artes Cênicas do Departamento de Artes Cênicas (DEART-IFAC) da Universidade Federal de Ouro Preto (UFOP). A prática aqui abordada foi desenvolvida na Escola Rodrigo de Melo Franco de Andrade - Fundação de Artes de Ouro Preto (FAOP), localizada na cidade de Ouro Preto - Minas Gerais, uma escola de referência em arte na cidade e região.

A experiencia relatada nessa pesquisa se propõem a repensar esse espaço escolar, explorando novas funções à objetos que parecem ter apenas uma e, com isso, brincar com as possibilidades, mergulhar no aspecto lúdico da linguagem teatral. Buscando inserir o aluno no âmbito do teatro pelos conceitos plurais da cenografia, materiais expressivos, o objeto em cena, e a caracterização do mesmo.

\footnotetext{
${ }^{1}$ Formada em Artes Cênicas Bacharel e Licenciatura pela Universidade Federal de Ouro Preto (UFOP). E-mail: jessicalpc_282@hotmail.com.
} 


\section{Objetivos}

Pequenos atos, mesmo que corriqueiros, são cheios de significados. Sentar numa cadeira, utilizar uma mesa, andar, entre outras ações, são atos que podem ter inúmeras formas. O objeto continua o mesmo, mas o que muda é a maneira como o vemos, utilizamos, significamos. Um dos objetivos dessa experiencia é abrir o olhar para além do cotidiano, ver o que é embutido na intenção que foi feita, por exemplo, uma cadeira, e ser capaz de dar a ela uma nova função ou até mesmo a "desfuncionalizar"2. Quero dizer com esse termo que os objetos que tem um uso específico para sua fabricação e a sua validade dura exatamente o período de exercício, e quando se dá um novo uso, principalmente no âmbito artístico, sobretudo no teatro com o uso lúdico, se está “desfuncionalizando” o objeto, tirando o seu caráter de fabricação, utilitário.

O intuito da proposta é o brincar com o espaço e os objetos da instituição. Com a essa pesquisa, questiono o espaço de escolarização, a função demarcada de seus objetos e alunos nesse espaço, e como repensar as formas desse espaço e proporcionar um espaço de expressão infantil.

\section{Metodologia}

Uma abordagem utilizada para instigar os participantes foi a contação de histórias. Fizemos uma história coletiva, usando um gravador, que passava de mão em mão, eles foram elaborando essa história de modo espontâneo. A história criada falava das aventuras de um Coelho que tentava construir sua casa, mas que no meio da história acaba morrendo, virando zumbi e decidindo morar no fundo do mar, com sua amiga Carpa.

Depois disso a oficina foi dividida em 4 momentos. O primeiro desenhar o animal como se imaginava, o segundo escolher um objeto da sala aleatoriamente, o terceiro misturar esse objeto com o animal, criando um personagem, ou um objeto que não era mais um objeto comum, mas um objeto transformado, “desfuncionalizado”. E por último, a transformação já tinha acontecido em desenhos, acontecer na pratica nos objetos reais. Para esse transformação utilizei da a teoria da bricolagem, que se utiliza da junção de materiais não esperados, fragmentados para se fazer algo novo, que não necessariamente tem relação com algum objeto comum, mas sim tem sua própria estética e simbologia.

Ao fim da experiencia eles manipularam o objeto como gostariam, transforma-lo naquilo que haviam desenhado e imaginado. Fazendo o uso da manipulação/animação de objetos, uma

\footnotetext{
${ }^{2}$ O termo “desfuncionalizar” surgiu de discuções e conversas com a Prof. Me. Thalita Motta Melo que orientou essa pesquisa.
} 
técnica do teatro de bonecos. Dessa forma eles deram ao objeto existência e história, falando de sua criação e sua trajetória.

\section{Resultados}

Assim nas primeiras partes do exercício a criança percebe os objetos presente na sala de aula, sabendo que juntos eles formam a cenografia da sala de aula, se arranjando e definindo o espaço. Após isso, ela classifica cada objeto, como por exemplo: o banco é para sentar, a mesa para apoiar para escrita, a lixeira para jogar o lixo fora, o quadro para escrever e assim por diante.

Cada grupo fez à sua maneira a transformação do objeto, criou o seu personagem, manipulando o objeto do cotidiano escolhido para que se tornasse um objeto expressivo, algo novo e cheio de possibilidades cênicas. Na finalização da experiencia, convidei os alunos a contar a história do seu personagem, improvisando com o objeto a história da maneira que quisessem, podendo manipular os mesmos como achassem mais adequado ou divertido. Interpretaram os personagens, falando sua história e contanto suas aventuras. As crianças foram os atores e autores de seus objetos, criaram e reinventaram o mundo a sua frente. Abaixo segue as imagens do resultado final das nossas invenções:
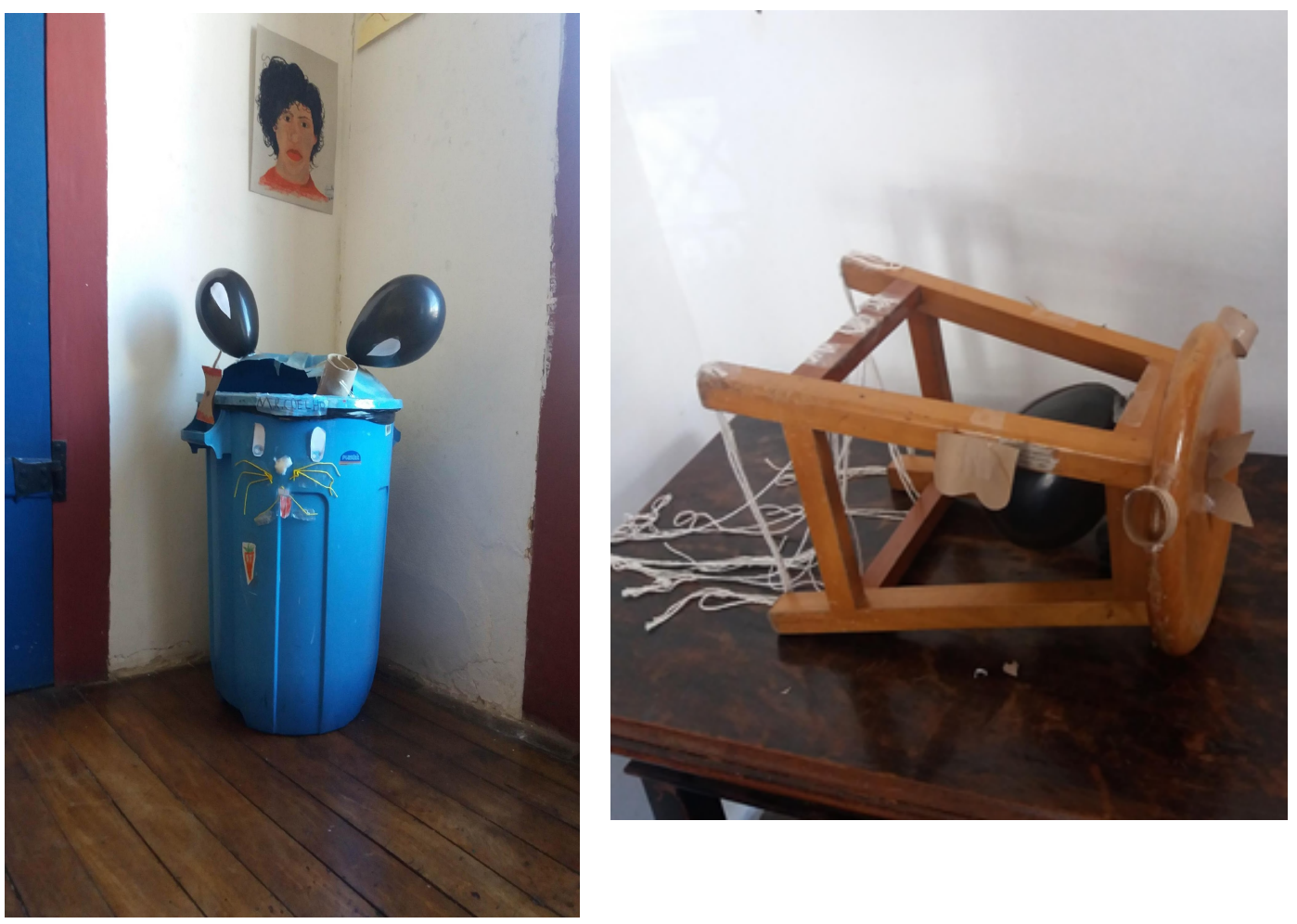

Mister Coelho e Senhora Carpa. Fonte: Acervo pessoal.

\section{Conclusão}


Ao atuar transformando o objeto, é possível se transformar também, fazer uma autorreflexão, descobrir-se também como um ser inacabado e perceber que existem infinitas possibilidades em aberto para serem exploradas não apenas na escola, mas no mundo. E esse conhecimento ocorreu em conjunto, por meio de troca de imagens (desenhos), palavras (contação de histórias), discussão e criação.

Acredito que houve a potencialização da liberdade expressiva, para além do espaço tradicional da carteira escolar, liberando a criança para uma maior expressão da sua corporeidade, dando vazão a sua espontaneidade, criatividade e reflexões sobre o processo de aprendizagem; dando voz a este protagonista da cena escolar. A partir da transformação que acontece em um pequeno espaço é possível estende-la para outros lugares, se perceber como um ser capaz de agir e refletir sobre suas ações e seu poder criador, e isso foi feito de uma maneira lúdica, onde o agir se torna brincar e o refletir uma troca entre crianças e adultos. Isso faz com que os alunos acessem maneiras de reflexão que confluem o racional e o emocional, fortalecendo a cognição e a si mesmos.

Essa prática foi uma parte importante da minha formação como uma professora de artes, de teatro, nela, junto com os alunos, expandi minha visão sobre a sala de aula, suas possibilidades, seus objetos, personagens escondidos por trás de objetos comuns e atores, manipuladores e criadores de um mundo que pode nascer a partir de um novo olhar. Percebo que o aluno tem agora uma nova compreensão das artes, de visões de mundo amplas, de ser capaz de se inserir dentro do mundo ao se redor de maneira única, e, se for da sua vontade, “desfuncionaliza-lo”. 